\title{
Article \\ Sustaining Synchronous Interaction Effectiveness in Distance Writing Courses: A Mixed Method Study in a KSA University
}

\author{
Murad Abdu Saeed ${ }^{1, *}$, Mohammed Abdullah Alharbi ${ }^{2}\left(\mathbb{C}\right.$ and Amr Abdullatif Yassin ${ }^{3}(\mathbb{C}$ \\ 1 English Department, Unaizah College of Sciences and Arts, Qassim University, Unaizah 52571, Saudi Arabia \\ 2 English Department, College of Education, Majmaah University, Al Majma'ah 15341, Saudi Arabia; \\ maalharbi@mu.edu.sa \\ 3 English Department, Center of Languages and Translation, Ibb University, Ibb, Yemen; \\ amryassin84@gmail.com \\ * Correspondence: mur.mohammed@qu.edu.sa
}

Citation: Saeed, M.A.; Alharbi, M.A.; Yassin, A.A. Sustaining Synchronous Interaction Effectiveness in Distance Writing Courses: A Mixed Method Study in a KSA University. Sustainability 2021, 13, 13675. https:// doi.org/10.3390/su132413675

Academic Editor: Jesús-Nicasio García-Sánchez

Received: 9 September 2021

Accepted: 7 December 2021

Published: 10 December 2021

Publisher's Note: MDPI stays neutral with regard to jurisdictional claims in published maps and institutional affiliations.

Copyright: (c) 2021 by the authors. Licensee MDPI, Basel, Switzerland. This article is an open access article distributed under the terms and conditions of the Creative Commons Attribution (CC BY) license (https:// creativecommons.org/licenses/by/ $4.0 /)$.

\begin{abstract}
The sudden transition to online learning during the COVID-19 pandemic has been challenging for many learners and teachers due to the fact that most universities suddenly shifted to online learning without providing adequate time for preparing and training teachers and learners in using interactive educational technologies. Such challenges are even more pronounced for language instructors in cultivating and sustaining interactions among learners, especially in writing courses that demand active engagement and interactions. Therefore, this study focused on what and how a writing instructor did through technology in creating an interactive writing environment for KSA learners joining five online writing courses and how learners perceived interactions and identifies the major factors affecting their perceptions. The data were collected from multiple sources: WhatsApp chats, Google Docs chats and comments, screencast recorded discussions, students' texts, and their responses to an electronic (e-) survey as well as follow-up interviews. The study revealed that in connecting Google Docs to the Blackboard Collaborate Ultra, the instructor engaged learners in multidirectional and multimodal interactions and text writing and revising. The WhatsApp group was also used for individual learner-learner and learner-teacher interaction illustrating support and consultation-seeking behaviors of learners beyond the online classroom time. The learners' perceptions of technology-mediated interactions (overall, learner-learner and learner-teacher) in the online writing courses were at high levels, though such perceptions varied according to several factors, including socio-demographic characteristics. The study concludes by offering useful pedagogical and research implications.
\end{abstract}

Keywords: sustaining interaction effectiveness; synchronous technology; distance writing; EFL learners' perception

\section{Introduction}

Writing a good text in English represents a challenging task for many learners of English as a foreign language (EFL), including EFL Arab learners. Therefore, one common pedagogical approach to teaching writing is to engage learners in peer writing since it is a healthy way to encourage learners to practice writing in English, exchange ideas and feedback, construct their knowledge and understanding, and collaborate towards a jointly written text through collaborative dialogue/interaction [1,2]. Despite this emphasis, students do not engage in spontaneously collaborative interactions $[1,3,4]$, especially in the target language [5]. This suggests that learners need support from writing teachers/instructors $[1,6,7]$.

While the above-mentioned challenges are often related to those learners joining face-to-face and or blended writing courses, what about these learners joining fully online writing courses? These challenges are more pronounced for students joining fully online language learning courses [8], including writing courses, especially during the global 
pandemic of COVID-19 when both learners and teachers are not given sufficient time to prepare for an online transition $[9,10]$. Saudi Arabia, the context of the current study, was no exception, as all universities have shifted to distance education during the COVID19 outbreak [11]. In fact, in such emergency online learning, sustaining interaction is important in order to reduce learners' feeling of physical and psychological distance and disconnection to their online learning environments [12]. However, how to sustain learners' interactions and communications in online language learning [13], and especially how to make the writing process more collaborative and dialogic, may turn out to be challenging for writing teachers and instructors [14].

Research has also provided evidence on the role of educational technologies in facilitating computer-mediated interactions in collaborative writing tasks in blended writing courses [15] with a body of research emphasizing synchronous tools, such as text and voice chats and conferencing in promoting immediate and real-time interactions among learners $[11,16,17]$. Google Docs is one of these interactive tools that promotes learnerteacher [18] and learner-learner interactions [19].

When available online, learners can synchronously interact through Google Docs text chat while composing and or editing their written texts $[15,18]$. Google Docs can be an effective tool when it is combined with other technological tools, such as Skype [20] and screencast capturing systems or tools, including Blackboard Collaborate Ultra [21]. Yet, technology may not be effective in promoting interaction unless it is combined with sound pedagogy [22]. In this regard, research on the increasing use of collaborative/peer writing in writing courses has provided evidence on collaborative writing as an instructional/pedagogical activity which promotes learners' interaction during the writing process [22-24]. It also encourages learners to share ideas, exchange feedback, and construct their written texts [24-26]. As learners engage in collaborative writing, they learn through peer discussions of the language used in writing [27]. While most of these previous studies have contributed to our understanding of the process of peer interaction in collaborative writing, they have focused on peer or learner-learner interactions in pairs and groups. What other patterns of interaction that might emerge in collaborative writing activities if the course instructor was the mentor and facilitator of such collaborative writing tasks? Research on teacher's involvement in interaction in collaborative writing highlights contradictory views; while a few researchers support the involvement of the teacher in interaction in peer work since it provides learners the opportunity to seek support not only from peers through learner-learner interaction, but also from teacher through teacher-learner and learner-teacher interactions [28,29], a few other researchers argue that this might minimize learners' engagement in collaborative writing [30], perhaps due to learners' perceived imbalance in teacher-learner interactions $[28,31]$. This suggests further investigation of the patterns of interaction in collaborative writing tasks mentored and facilitated by the course instructor through a combination of different technologies. In addition, students ${ }^{\prime}$ perception of such interaction is important in order to provide enriching insight into this topic from different aspects. Therefore, by combining Google Docs with mobile instant messaging through WhatsApp and Blackboard Collaborate Ultra in three online writing courses in a KSA university, the present study attempted to address the following research questions:

1. What are the patterns of interaction promoted and sustained through a combination of technological tools and a collaborative writing approach in the selected online writing courses?

2. How did the EFL learners joining the three online writing courses perceive the technology-supported interaction in peer writing?

3. How did the learners' factors (e.g., learner-related factors and technology-related factors) affect their interaction in these three online writing courses? 


\section{Theoretical Perspective on Interaction}

The current study was grounded on three important theoretical approaches to collaborative writing: the interactionist approach, sociocultural theory, and the socio-constructivist approach. For the interactionist approach, specifically the output hypothesis, interactional modifications which result from learners' meaning negotiations play a crucial role in facilitating language learning [32]. "Meaning negotiation refers to interactive feedback" [16] (p. 46). In other words, as learners negotiate meanings, they are more likely to exchange clarification requests, interpretations, confirmation checks, and reformulations [32]. These interactional exchanges help learners during interaction to modify the input into output [33].

From sociocultural theory [34], learning is theorized as a social activity that occurs within the zone of proximal development (ZPD) or in mediated interaction. Research influenced by this theory provides evidence on the role of dyadic interaction in assisting learners to successfully accomplish their learning tasks as a result of the mediation or scaffolding (support or assistance provided by more knowledgeable or more competent learners to less component ones) $[7,35]$. This theory emphasizes the dialogic and dynamic nature of peer interaction [5]. Moreover, research has emphasized the need for involving learners in collaborative work wherein learners jointly write their texts through peer interaction [1]. Language learning takes place in the social interaction process rather than in the writing products [2].

From the socio-constructivist perspective, recent research has also argued that engaging learners in peer work is necessary for promoting peer-peer or learner-learner interaction [36]. It is also one of the new ways of effective feedback delivery [37] and strengthening the socio-relational or socio-affective aspects of dialogic feedback [38]. In a review study of dialogic feedback [39], peer-to-peer dialogue is argued to promote learners' roles as seekers and givers of feedback. In other words, peer dialogue allows learners to mutually responds to and give feedback on each other [40,41]. Some socio-constructivist studies also highlight the role of teacher-learner interactions in developing learners' awareness of audience, clarifications of ideas, and revisions [28], as well as understanding of their writing [29] and exchanging feedback [42].

\section{Computer-Mediated Interactions}

Synchronous CMC tools, including conferencing chats, provide learners space for collaborative dialogue by which they engage with each other's contributions though question-response exchanges, opinions, utterance modification, agreement and disagreement, and confirmation checks in collaborative learning [5]. Such interaction resembles FTF interaction since it leads to message and meaning negotiations among learners [16]. In relation to collaborative writing, synchronous peer interaction helps learners to exchange immediate or timely interactive feedback on their errors and writing problems and make writing more comprehensible and meaningful [16]. It also provides learners an avenue to exchange ideas for their written texts and reflect on the language used by them in the dialogue by eliciting, questioning, and exchanging feedback [2]. According to [16], synchronous CMC chats engage learners in negotiating the meaning, discussing the content, offering error corrections, and managing their tasks, as well as talking about social matters irrelevant to the task.

One of the tools that promotes collaborative dialogue between learners is Google Docs. It fosters synchronous interaction through its text chatting box when both learners are available online [13,38]. The commenting feature of Google Docs can be also used by learners for peer interaction by developing conversation threads [43]. Empirical research reported that Google Docs facilitates learner-learner and learner-interaction around feedback through which they exchange questions and responses, clarify their intentions, and provide explanations of their ideas [7,20].

Other educational technologies, besides Google Docs used in this study, which are claimed to facilitate learner-learner and learner-teacher interaction and enrich online learn- 
ing environments are mobile instant messaging and the Blackboard Collaborate Ultra. Mobile instant messaging through WhatsApp provides learners the opportunity to keep in touch with peers, promote their peer discussions, and engage them in collaborative learning through instant feedback $[38,44]$. Learners were also found to engage in peer discussions and understand their peers through mobile instant messaging beyond the classroom [45]. Mobile instant messaging helps learners to exchange immediate feedback on their language use [46]. Blackboard Collaborate Ultra, which is a synchronous video/screencast recording system, provides space for learners to interact with peers and teachers during online classes in real time $[47,48]$.

From the above literature on $\mathrm{CMC}$ interaction in language learning and writing courses, most of the previous studies on synchronous interaction have focused on one technological tool and, therefore, have restricted interactions to the text mode. Therefore, in this study, the rationale for combining the three technological tools was that learners would be able to flexibly switch from one tool to another and from a voice mode to a text mode [43]. For instance, the potential of Google Docs for interaction can be maximized by combining it with screencast records [20] or social networks such as Skype, which enable learners to increasingly interact with each other and quickly switch from and to text and audio chats [20]. In addition, bi-modal technologies combining voice and text modes are argued to be efficient in increasing learners' interaction and participation in writing activities $[16,43]$.

\section{Hypothesis Development}

This study developed two hypotheses that are related to providing the quantitative data of the second research question. In terms of learner-learner interaction, several studies have provided useful insight into learners' perceived value of online interaction, particularly learner-learner and learner-teacher interactions for their learning and development [49-51]. These studies have also provided evidence on learners' varying perceptions of online interactions according to their socio-demographic factors, such as age, gender, learning experience, and other factors related to technology, including the media used for interactions. Therefore, it is postulated that:

Hypothesis 1 (H1). Learner-learner interaction significantly impacts interaction effectiveness of online writing activities among university students.

In relation to learner-teacher interaction, due to its features, including voice and text chats, file sharing, web page browsing, recording, and break-out-for small group discussions, Blackboard Collaborate Ultra facilitates real-time or immediate interactions and spontaneous idea and feedback exchange [14]. In addition, interaction through Blackboard Collaborate Ultra is multidirectional, for it occurs between target learners or learners who are owners of the task and between target and non-target learners and their teachers [52]. It is also described as multimodal since it is a mixture of verbal (oral and text) and non-verbal (pictures, video, etc.) factors [47]. Hence, it hypothesized that:

Hypothesis 2 (H2). Learner-teacher interaction significantly impacts interaction effectiveness of online writing activities among university students.

\section{Method}

The present study used a mixed-method research design to answer the above-stated research questions. Specifically, the concurrent triangulation strategy suggested by [53] was used, which combines interaction data, a survey, and a follow-up interview. The data were analyzed separately, but were mixed when presented in the findings section, especially when answering the second and third research questions. 


\subsection{Study Setting}

The target population of this study was the EFL learners joining the English Department in a Saudi university. Specifically, using a convenience sampling strategy, 204 EFL learners joining online writing courses were chosen as the study sample. The students were taught these writing courses by one instructor, an assistant professor in English with five years of experience in teaching writing. However, out of the overall number (204) of students, 190 students responded to the online survey, $74.64 \%$ of which were females while $35.36 \%$ of them were males.

\subsection{Data Collection}

Three types of data were collected during the second semester of the academic year of 2020-2021: the interaction, students' responses to the online survey, and students' followup interview. The interaction data were collected from WhatsApp chats, Google Docs chats and comments, and screencast-recorded discussions in Blackboard Collaborate Ultra. These data were collected over the semester. The online survey was developed from a previous study on interaction [50] with some modifications to suit the purpose of this study and writing courses. The survey was tested for convergent and construct validity using Structural Equation Modelling (SEM) in Smart-PLS software, and it achieved the required values, which will be discussed in Section 5.2. The survey consisted of three sections: demographic characteristics (four items), learner-learner interaction (six items/statements), learner-teacher interaction (six items), and the dependent variable was online interaction effectiveness (four items). The items in the last two sections are meant to elicit learners' responses using a five-point Likert scale: (1) Strongly disagree; (2) Disagree; (3) Neutral; (4) Agree; (5) Strongly agree. The survey was administered to students enrolled in the three courses at the end of the semester by distributing its link to the course WhatsApp groups. Students were also given a consent to sign and informed of the confidentiality and research purpose. They were also informed of their voluntary participation and that they had the right to withdraw at any time. Only 190 students responded to the online survey. Table 1 shows the constructs of the current study.

For the follow-up interview, several questions that seek learners' elaboration on their responses to the online survey and elicit their detailed views on interaction were developed by the researchers and validated by two field experts for content validity. Based on the experts' feedback, the questions were revised. Then, the follow-up interview was announced to students, scheduled, and conducted by one of the researchers through Zoom Meeting voice calls. Although 43 students were selected based on their willingness to take part in the interview, only 28 of them were interviewed.

Table 1. Constructs of the study.

\begin{tabular}{|c|c|c|c|c|}
\hline Construct & IV/DV & Source & & Items \\
\hline $\begin{array}{l}\text { Learner-Learner } \\
\text { Interaction (LLI) }\end{array}$ & IV & & $\begin{array}{l}4 . \\
5 . \\
6 .\end{array}$ & $\begin{array}{l}\text { I communicate with my fellow students } \\
\text { through multiple communication channels } \\
\text { (e.g., email, phone, discussion board, and } \\
\text { online chat) in my online courses. } \\
\text { I have opportunities to communicate with my } \\
\text { classmates online in real time. } \\
\text { Communication between me and other } \\
\text { students in my online classes is a dynamic } \\
\text { two-way communication. } \\
\text { I actively engage in dialogues with other } \\
\text { students to construct and share knowledge. } \\
\text { I value my communication with my } \\
\text { classmates on course-related issues. } \\
\text { My communication with my classmates in the } \\
\text { online classes is intensive. }\end{array}$ \\
\hline
\end{tabular}


Table 1. Cont.

\begin{tabular}{|c|c|c|c|}
\hline Construct & IV/DV & Source & Items \\
\hline $\begin{array}{l}\text { Learner-Teacher } \\
\text { Interaction (ICC) }\end{array}$ & IV & & 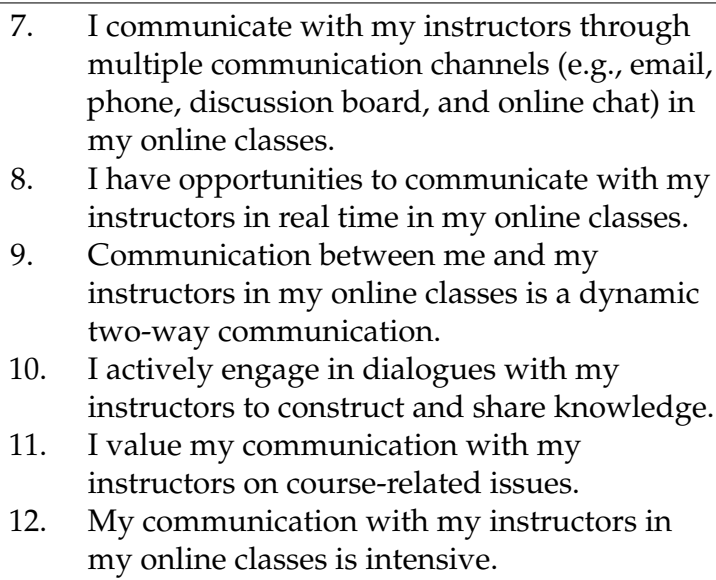 \\
\hline $\begin{array}{l}\text { Interaction } \\
\text { Effectiveness } \\
\text { (INTERA) }\end{array}$ & DV & & $\begin{array}{l}\text { 13. My communication with my classmates in my } \\
\text { online courses is constructive/helpful in } \\
\text { achieving learning objectives. } \\
\text { 14. My communication with my classmates in my } \\
\text { online classes is something I look forward to. } \\
\text { 15. My communication with my instructors in } \\
\text { my online classes is constructive/helpful in } \\
\text { achieving learning objectives. } \\
\text { 16. My communication with my instructors in my } \\
\text { online classes is something I look forward to. }\end{array}$ \\
\hline
\end{tabular}

\subsection{Data Analyses}

\subsubsection{Qualitative Data}

The interaction data were analyzed inductively and deductively (taking into account previous research). However, due to the large volume of the interaction data collected from different sources, i.e., WhatsApp chats, Google Docs chats and comments, and screencast records, especially the screencast records $(\mathrm{N}=102$ records varying in volume from $48 \mathrm{~min}$ to $127 \mathrm{~min}$ ), it was sufficient to analyze the interactional episodes by answering certain questions in relation to (1) the characters involved in the interaction, (2) initiating and responding moves, (3) interaction mode(s), (4) the technological tool(s) used, and (5) the context (activity or writing stage). Table 2 illustrates our interaction analysis of Excerpt (1) extracted from paired learner-learner synchronous discussions on a highlighted sentence in Google Docs (Scheme 1).

Table 2. Coding of a sample interaction episode using international analysis.

\begin{tabular}{|c|c|c|}
\hline $\begin{array}{l}\text { Questions Guiding the } \\
\text { Interaction Analysis }\end{array}$ & Points of Focus & Answers \\
\hline Who? & Characters & $\begin{array}{c}\text { S2P8 as the initiator } \\
\text { S1P8 as the respondent }\end{array}$ \\
\hline What? & $\begin{array}{l}\text { Initiating and responding } \\
\text { moves }\end{array}$ & $\begin{array}{l}\text { Initiation: Failure to interpret } \\
\text { Responses: Interpreting + reasoning + } \\
\text { surprise + question + suggesting }\end{array}$ \\
\hline How? & $\begin{array}{l}\text { Interaction mode(s) and } \\
\text { technological tools }\end{array}$ & $\begin{array}{l}\text { Voice \&-text } \\
\text { Blackboard My Group combined with } \\
\text { Google Docs }\end{array}$ \\
\hline Where? & The interaction context & $\begin{array}{c}\text { During the revision stage: the whole } \\
\text { class discussion }\end{array}$ \\
\hline
\end{tabular}


writing is that it is very diverse and creative. You can go anywhere in

the world, describe anything in life, or even change people's

thoughts. Writing is important in human life because it brought

information from ancle $D$ peoples through books and novels. Writing

Scheme 1. An illustration of a highlighted sentence in Google Docs resulting into interaction.

S2P8: بس مافهمت اللي في اللون الاخضر المائل But I could not get the sentences in green colour highlights and italics (Voice)

S1P8: Oh that means not related to the topic because I guess the sentences talk about importance of writing not the writing class. (Voice)

S2P8: Wow you are genius! (Written)

S1P8: Thank you. (Voice)

S1P8: So can we remove them? (Written)

S2P8: Yes or we can change them by others related to our topic. (Written)

Based on our above interaction analyses of the identified episodes, we could cluster the interactions into (1) learner-learner interaction, (2) teacher-learner interaction, and (3) learner-teacher interaction, which are discussed in detail in the findings section.

Finally, the follow-up interview was analyzed using a thematic analysis to partially answer the second and third research questions. The analysis was performed by two independent researchers. The comparison resulted in $92 \%$ agreement and, after discussions, the agreement reached $95.52 \%$. To maintain anonymity, pseudonyms for the interviewed learners (S1P1, S2P1), according to the numbers of the pairs they had been assigned to during the peer writing activities, and $(\mathrm{T})$ for the instructor were used in this study, especially when reporting the interaction and interview data.

\subsubsection{Quantitative Data}

The quantitative data were analyzed with the Smart PLS program, and the PLS estimates were reported using [54]'s recommendations as well as [55]'s two-step technique. A total of 190 samples and 5000 bootstrapping samples were used to test both the measurement and structural models [54]. There were no missing values in the data, so no replacement measurements were required.

\section{Findings}

6.1. Patterns of Interaction in the Online Writing Courses Sustained through Technological Tools and Instructional Designs

In answering the first research question, the interaction in the online writing courses was leveraged in multiple directions and modes using different technological tools and instructional strategies. Therefore, this section presents the findings according to themes that illustrate such multidirectional and multimodal interaction.

\subsubsection{Learner-Learner Interaction}

Most of the interactions, especially during the task planning and writing stages, took place in the WhatsApp groups and Google Docs connected to Blackboard Collaborate Ultra. This interaction demonstrated how the paired learners planned their tasks by selecting the topics, brainstorming, and generating ideas for their writing tasks (See Scheme 2). As they did so, they exchanged text and audio messages and even pictures of the lectures and handbooks in order to refer to particular points and guidance given in the online lectures. Some of them used English, while some others used Arabic and even sometimes mixed both Arabic and English. 


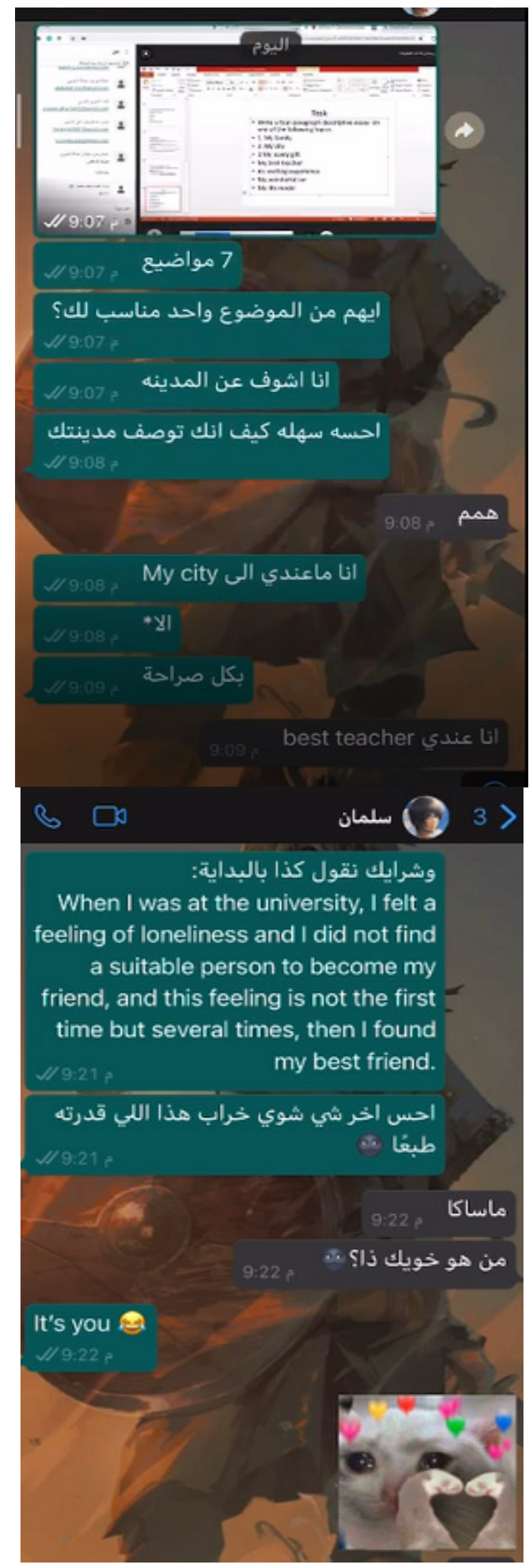

Scheme 2. An illustration of learner-learner interaction during the planning stage. 
These discussions were later converted into written texts by developing the ideas into first drafts of short essays through Google Docs (See Scheme 3). During the peer writing stage, the paired learners also interacted over their writing by focusing on transforming of the generated ideas into full sentences, paragraphs, and essays, which were read and their errors were highlighted by the instructors for peer revision discussions through Blackboard Collaborate Ultra (My groups).

$$
\text { P4 }
$$

My lovely gift

\begin{abstract}
When I was at school, I was feeling lonely and I did not find a person who I can call my best friend. I felt this loneliness several times. however One day I found my best friend whom I had always looked for a long time ago.

The name of my friend is Salman, and my first meeting with him was after the end of the listening and conversation class. The first impression was somewhat strange because I noticed on his mobile phone a background of the anime characters. Honestly, I love watching anime and playing the Playstation so I talked with him and we exchanged dialogue. We were always talking about anime, video games and even studying. It was a really fun moment for me. It is true that what you may see is strange because it is rare to find someone who understands you, but believe me, when you find someone who loves the same things you like, you will know how I'm feeling. When you talk with someone about the same interests you will feel comfortable
\end{abstract}

Scheme 3. An illustration of the first draft of a jointly written text.

Learner-learner interaction was also promoted by the instructor's highlights of paired learners' first drafts of essays written in the revision stage. However, at this stage, the interaction occurred in Blackboard Collaborate Ultra (My groups) connected to Google Docs pages (See Scheme 4). These peer interaction activities started by assigning each pair of learners to the Blackboard Collaborate Ultra (My groups) of each course (Pic1 on the left). Then, by clicking on Collaborate (Pic2 on the right), the paired learners were able to join their synchronous screencast discussion rooms (Pic3 on the left) where they could record their voice communication (Pic4 on the right) and also text chat while editing their Google Docs-based writing displayed on the screen (Pic5 at the bottom).

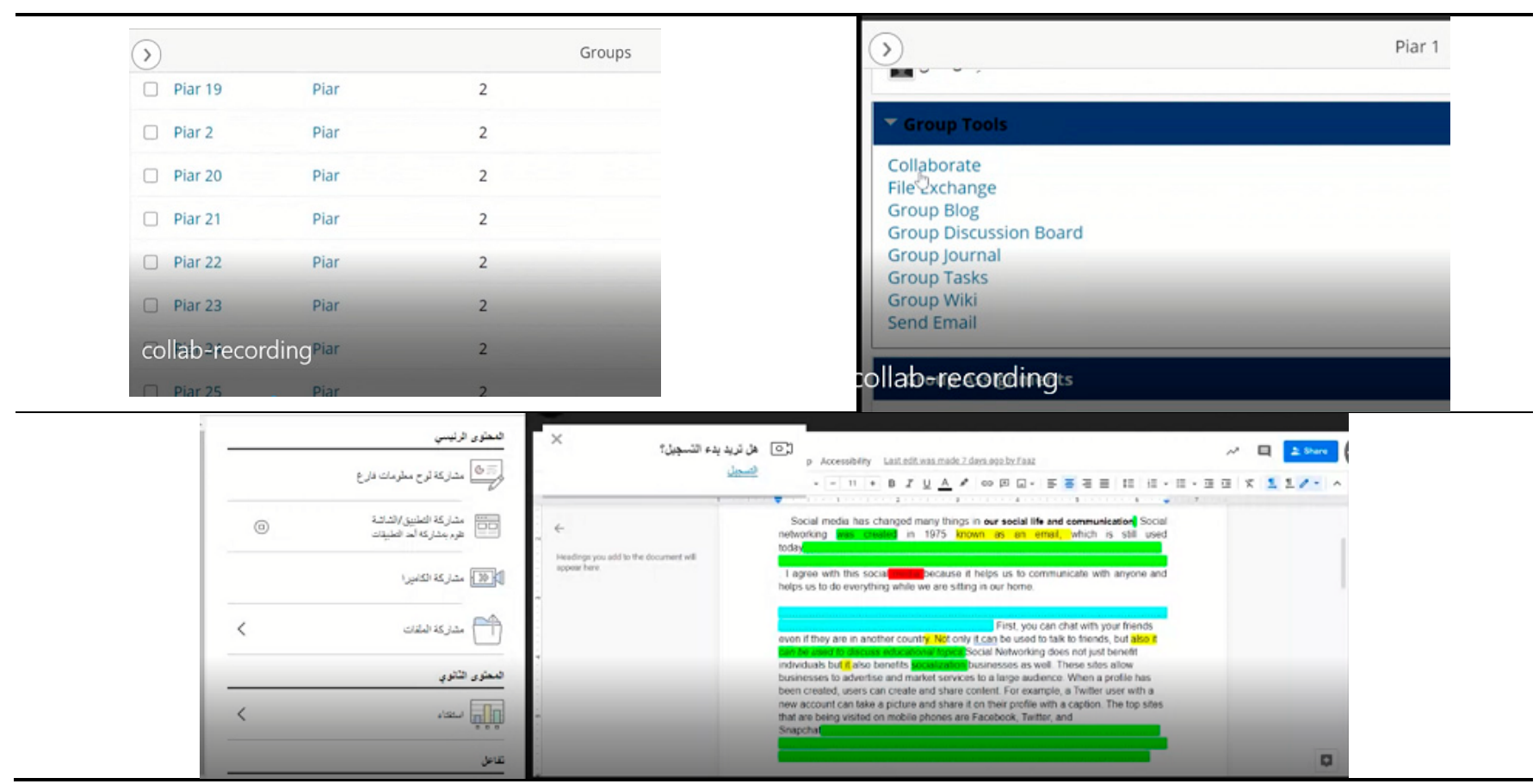

Scheme 4. An illustration of learner-learner interaction in the Blackboard Collaborate Ultra Groups connected to Google Docs pages. 
As the paired learners engaged in peer interaction using Blackboard Collaborate Ultra, they often talked via the voice mode and recorded lengthy screencasts (varying from $48 \mathrm{~min}$ to $127 \mathrm{~min}$ ). Such records demonstrated how interaction peer promotes learners' interpretation and negotiation of feedback highlights, explanation, elaboration, suggestion, and question-response exchanges. This is illustrated by Excerpt (1), extracted from Pair 8's screencast discussion (Scheme 5), wherein the interaction was initiated by S2P8's expression of failing to understand the green-highlighted issue in their text. In responding to him, S1P8 attempted to figure out the type of error. As the interaction evolved, S2P8 praised his peer for his error interpretation, which was appreciated by S1P8. The interaction seemed to end with S1P8's request to remove the highlighted sentences, which was accepted by S2P8. This interactional episode also shows how the paired learners were able to easily switch from the voice to the text modes in their interaction.

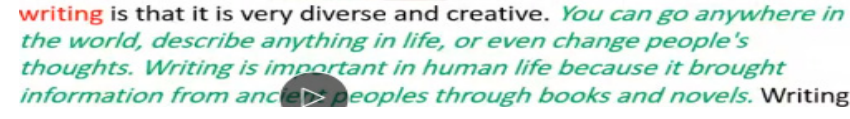

Scheme 5. An illustration of a highlighted flaw in writing.

S2P8: بس مافهمت اللي في اللون الاخضر المائل But I could not get the sentences in green colour highlights and italics (Voice)

S1P8: Oh that means not related to the topic because I guess the sentences talk about importance of writing not the writing class. (Voice)

S2P8: Wow you are genius! (Written)

S1P8: Thank you. (Voice)

S1P8: So can we remove them? (Written)

S2P8: Yes or we can change them by others related to our topic. (Written)

\subsubsection{Teacher-Learner Interaction}

This type of interaction was initiated by the instructor through the text chat and commenting boxes of Google Docs (See Scheme 6). When the instructor and the paired students were available online, as shown by the three circled profile users on the right corner of the Google Docs page, such interaction was synchronous and timely. The instructor initiated this interaction with the paired writers of the texts by asking questions in the form of text messages in the chat box and also comments inserted into their essays, specifically the erroneous parts of essays. Consequently, the paired learners responded to the questions, interacted with the instructor, and also asked questions seeking clarification, confirmation, and so forth. However, in a few cases, teacher-learner interaction was asynchronous when the paired learners were not online while the instructor was commenting on their texts. Yet, the learners responded to the instructor's questions and also extended the interaction by commenting and responding to these comments at different, delayed times, thus creating threads of interactional comments on Google Docs.

However, since this interaction appeared time-consuming for the instructor, the writing instructor shifted it to the whole class discussions later held during the writing lectures. Teacher-learner interaction (whole class) occurred as a result of connecting the whole class Blackboard Collaborate Ultra to Google Docs-based writing of particular pairs of students during the writing classes. This type of interaction was initiated by the instructor through display of the Google Docs-based writing in the Blackboard Collaborate screen to the whole class and highlighting the pair's errors (See Scheme 7). As initiation moved, these highlights were often accompanied by the instructor's verbal voice comments serving as questions and eliciting learners' interpretations of errors and suggestions on how to fix the detected errors (Excerpt 2). Such highlights acted as stimulators of learners' thinking and dialogue. This dialogue was pursued by both writers of the text being discussed as they were available online in their Google Docs pages and also in the virtual Blackboard Collaborate Ultra room. However, the interaction was also extended by the instructor to those learners who were not the writers of the text through questions asking the whole 
class and, sometimes, naming individual learners to respond and give suggestions on the highlighted errors.

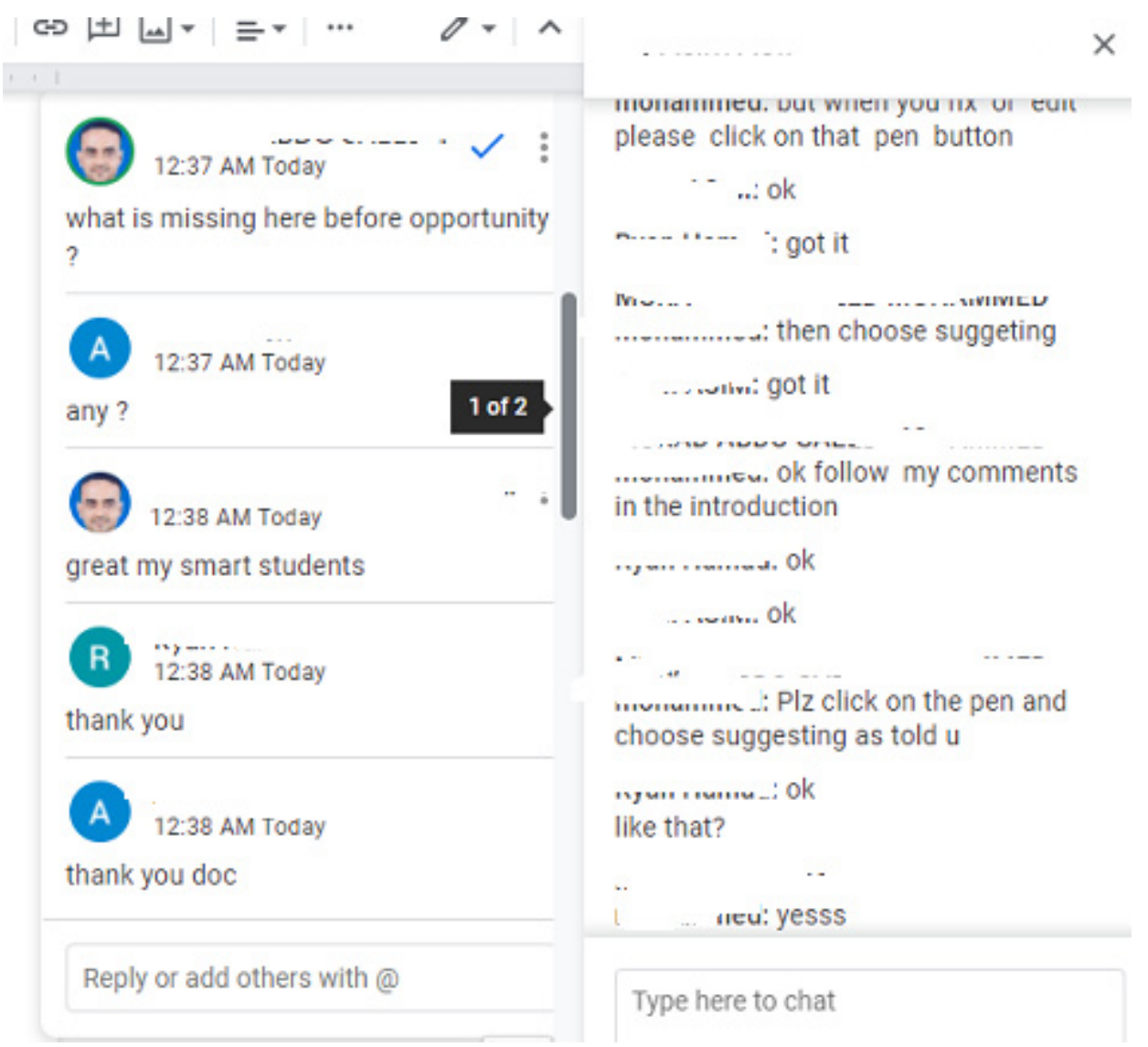

Scheme 6. An illustration of teacher-learner interaction in Google Docs.

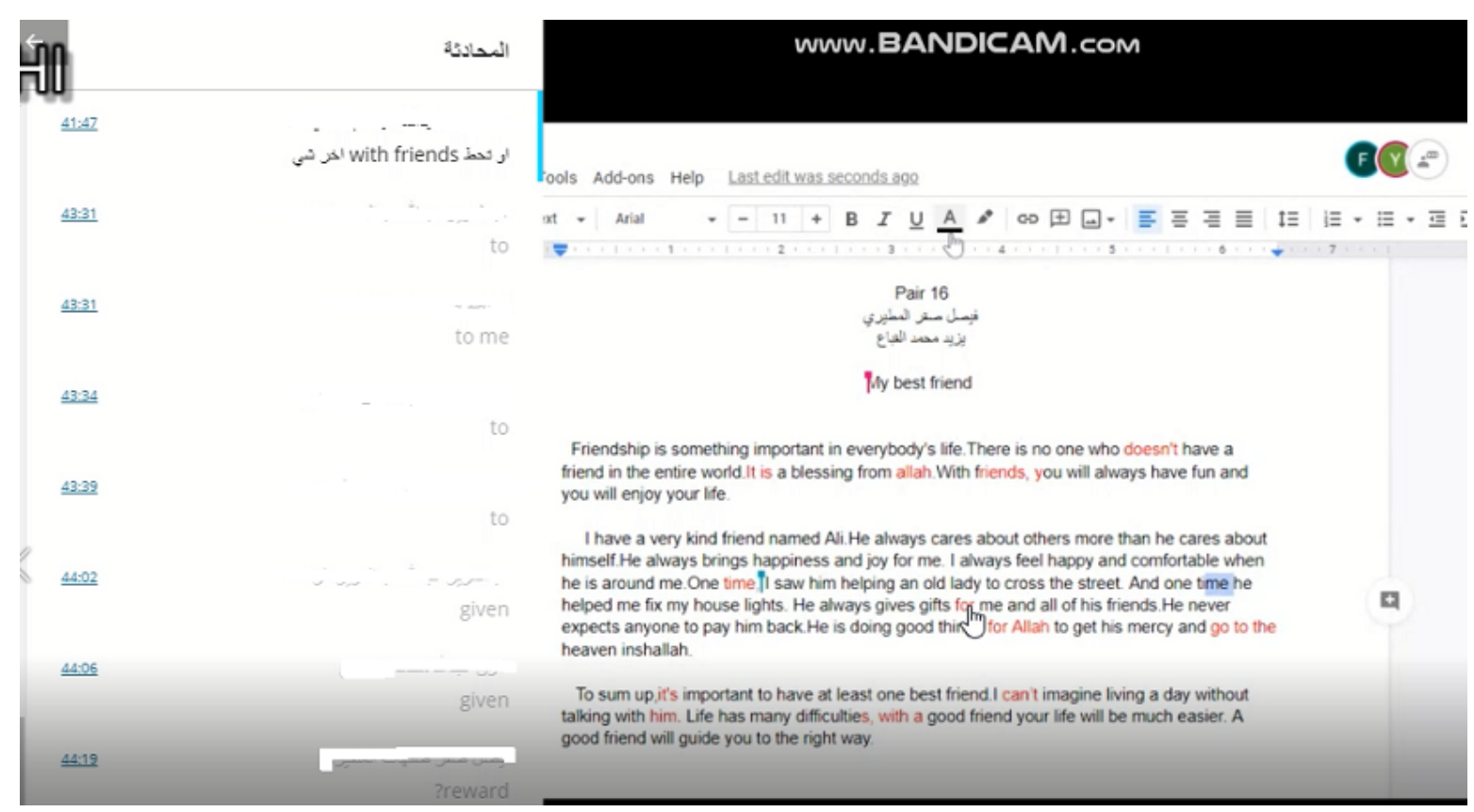

Scheme 7. An illustration of whole class discussion via the Blackboard Collaborate Ultra connected to Google Docsbased writing. 
Excerpt (2) demonstrates a case in which student-writers (Pair3) kept silent, but student-non-writers (S2P7, S1P13, S2P10, and S2P8) responded to the teacher's initiating moves. Such an interaction showed how student-writers act as unresponsive to dialogic interaction, but later respond to it through editing their texts in Google Docs, as exemplified by S2P3's replacement of the word "emotion" with "expressions". It also demonstrated how no-writers were responsive and contributing to the dialogue through clarification, suggestions, explanations, and error interpretation, giving accurate forms and meanings and providing peer feedback.

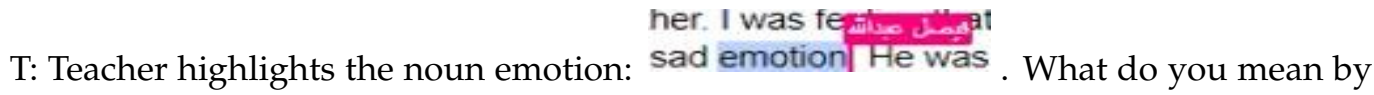
this? (Highlight + Voice in SSF sessions)

P3: Silent.

T: Asking the class: Do you know its meaning? (Voice)

S2P7: It means sad feelings Dr. (Written)

T: Oh great but does not it look general? (Voice)

S1P13: يعني تيهه يغيروها دكتور Do you want them to change it? (Voice)

T: I think yes better to make it specific. (Voice)

S2P10: So what about feeling? (Written)

T: I guess it is still the same. Calling student-authors by names. You can change it into expression. You know expression? (Voice)

S2P8: Yes Dr. تعابير(Expressions). (Written)

T: Spelling out the word: E-X-P for people -R-E-Double SS-I-O-N. (Voice)

S2P3: Deleting "emotion" and replacing it with "expression" following the teacher's

spelled out alphabets of the word. sadexpremotion. (Written through Google Docs suggested edits)

T: Bravo now. (Voice)

\subsubsection{Learner-Teacher Interaction}

This pattern of interaction was initiated by both writers and non-writers. Interaction initiated by the writers often occurred when paired writers failed to interpret or understand some of the instructor's comments on their texts through Google Docs (Excerpt 3A) and, in some cases, when one of the paired authors sought feedback on major corrections of their texts (Excerpt 3B) through WhatsApp messages. Both excerpts are evidence on learners shift to learner-teacher interactions using interrogatives. Both excerpts illustrated how writers initiated the dialogue by showing their failures to discern the intent of feedback highlights on their text, questions seeking support, as well as statements expressing their misunderstanding of particular feedback highlights.

S1P9: Sorry Dr. We were discussing this comment but we couldn't get it.

T: So what do you think about it? Does it reflect the body?

S1P9: Oh I think we need to be more specific so can we write it again?

S2P9: Sorry we planned to delete it.

$\mathrm{T}$ : Why deleting it?

S1P9: Can we make them more focused? How is it now Dr.?

T: Great for you.

S1P12: Hi doctor. You told us to change the entire body so we changed it but I don't know if you checked it. Because I am afraid to submit it with mistakes. (Written)

T: You can refer back to the recorded session. (Voice)

S1P12: Doctor. We are pair 12, and you told us to change the entire body, but it seems you have not seen it yet. (Written).

S2P12: Ok Doctor but can you read the body we changed to see the errors if you are free? (Voice).

T: Ok wait. (Written) 
S1P12: Ok take your time Doctor. (Written)

$\mathrm{T}$ : So what do you think of the comment?

S1P12: I think you wanted us to be more specific. Am I right dr? (Written)

T: Great so do it. (Voice)

As this dialogue was sometimes initiated by non-writers who were attending the discussions, it was initiated through a question-seeking clarification and/or instruction from the instructor on certain errors in their classmates' essays being discussed (Excerpt 4). Since the instructor did not respond to these questions directly and explicitly, but rather directed such questions to the whole class, the instructor sustained the dialogue by inviting diverse responses from other students and extended the dialogue. Such dialogue reflects diverse perspectives.

S1P14: Raising hand sign in the whole class session.

T: Yes (calling his name). Any question? (Voice)

S1P14: I am sorry Dr. to disturb you. But why you asked Pair 10 to change the tense to the present perfect? (Voice)

T: A great question. Who can answer it? (Voice)

S2P5: Easy. (Written)

S2P6: Because to talk about things during a period stated from the past. (Written)

T: Great but what do you mean from the past? Can you give an example? (Voice)

S2P6: Silent.

T: Who can give an example? (Voice)

S2P10: We have been friends since our secondary school days. (Written)

T: Bravo and an excellent example. So what words and phrases do we usually use for this tense? (Voice)

S2P13: For and since. (Written)

T: Great and is it clear now? (Voice)

S1P14: Yes got it. Thank you all. (Written)

\subsection{Learners' Perception of Technology-Facilitated Interaction}

In answering the second research question, the findings are presented through a mixture of quantitative and qualitative data, point by point.

\subsubsection{Measurement Model}

The current study used the reflective measurement methodology, which includes two types of validity assessments: convergent and discriminant validity. The degree to which the construct's indicators converge or share a significant proportion of variation in common is referred to as convergent validity [54]. In addition, Ref. [56] proposed factor loadings and AVE to examine convergent validity; the results of this evaluation are provided in Table 3, and Figure 1 depicts the measuring model, in which all components are reflected.

Table 3 displays the indicator loadings, Composite Reliability (CR), and Average Variance Extracted (AVE) of the reflecting constructs. Loadings that were higher than the suggested value of 0.700 were kept [56]. LLI, LTI, and ITERA goods were sufficient since additional items with high loading scores complement AVE and CR [56,57]. Furthermore, after the item-deletion procedure, all three constructs met the threshold values/minimum cut-off values for CR and AVE, since all CRs were greater than 0.7, all AVEs were greater than 0.5, and Cronbach's Alpha values of all the constructs were higher than 0.7 [56]. At this level of the measurement model evaluation, the constructs were found to meet the requirements for reliability and convergent validity. 
Table 3. Reliability and convergent validity.

\begin{tabular}{|c|c|c|c|c|c|}
\hline Construct & Items & Loadings & $\begin{array}{l}\text { Composite } \\
\text { Reliability }\end{array}$ & $\begin{array}{l}\text { Average Variance } \\
\text { Extracted (AVE) }\end{array}$ & Cronbach's Alpha \\
\hline \multirow[t]{4}{*}{ Interaction Effectiveness } & ITERA1 & 0.749 & 0.877 & 0.641 & \multirow{4}{*}{0.814} \\
\hline & ITERA2 & 0.814 & & & \\
\hline & ITERA3 & 0.829 & & & \\
\hline & ITERA4 & 0.809 & & & \\
\hline \multirow[t]{6}{*}{ Learner-Learner Interaction } & LLI1 & 0.820 & 0.931 & 0.694 & \multirow{6}{*}{0.912} \\
\hline & LLI2 & 0.816 & & & \\
\hline & LLI3 & 0.772 & & & \\
\hline & LLI4 & 0.853 & & & \\
\hline & LLI5 & 0.881 & & & \\
\hline & LLI6 & 0.851 & & & \\
\hline \multirow[t]{6}{*}{ Learner-Teacher Interaction } & LTI1 & 0.857 & 0.922 & 0.664 & \multirow{6}{*}{0.899} \\
\hline & LTI2 & 0.874 & & & \\
\hline & LTI3 & 0.772 & & & \\
\hline & LTI4 & 0.824 & & & \\
\hline & LTI5 & 0.808 & & & \\
\hline & LTI6 & 0.746 & & & \\
\hline
\end{tabular}

Note: INTERA = Interaction effectiveness, LLI = Learner-learner interaction, and LTI = Learner-teacher interaction.

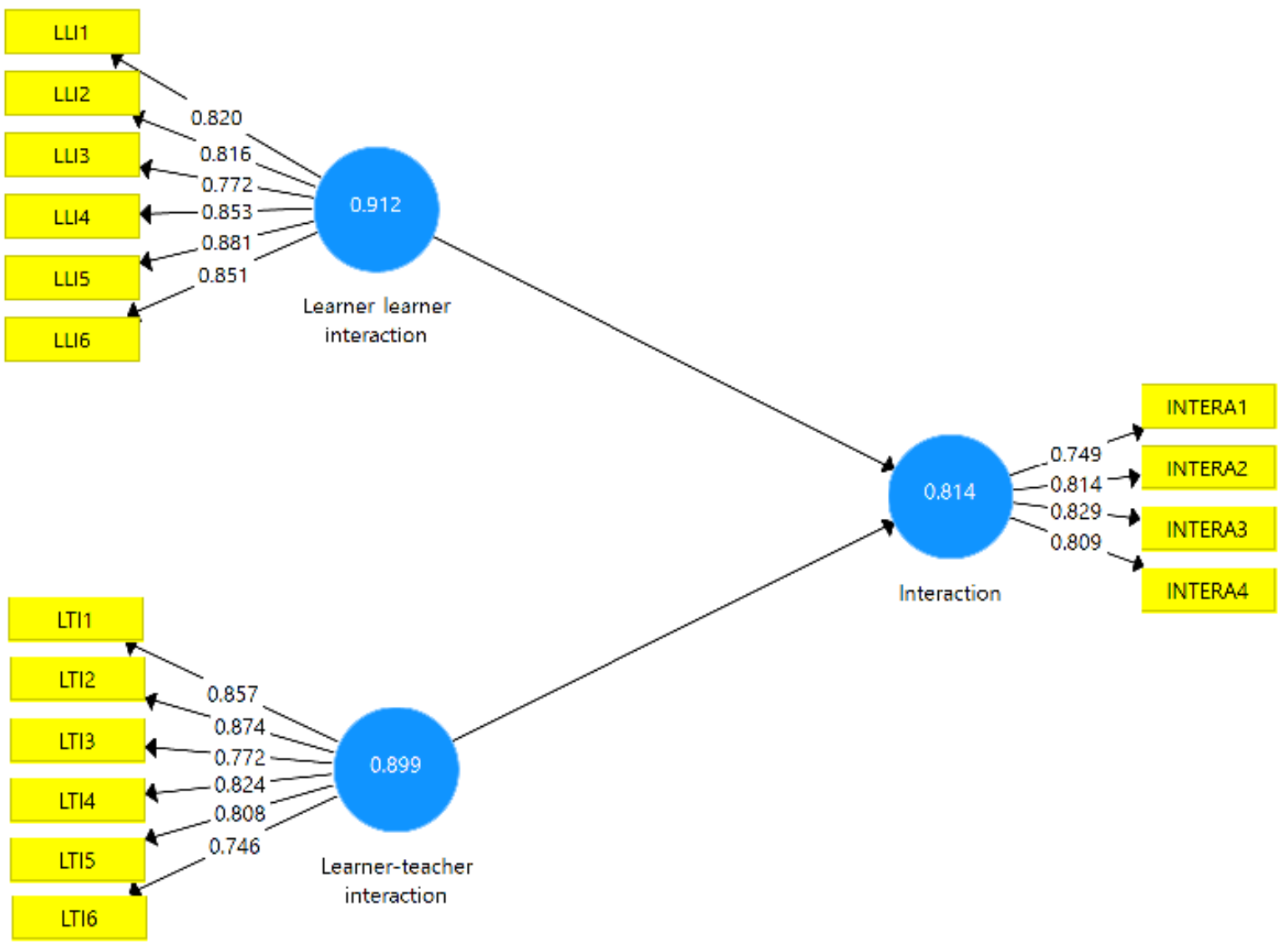

Figure 1. Measurement model assessment.

As a result, the model's discriminant validity was evaluated, with the indicators loading more strongly on their own constructs than on the other constructs in the model, and the average variance shared between the construct and its measures being greater than the variance shared between each construct and the other constructs [58]. Table 4 shows 
that all reflective constructs had sufficient discriminant validity [58], as measured by the square root of AVE (diagonal) being greater than the correlations (off-diagonal).

Table 4. Discriminant validity using Fornell and Lacker criteria.

\begin{tabular}{cccc}
\hline & Interaction & Learner-Learner Interaction & Learner-Teacher Interaction \\
\hline Interaction & 0.801 & & \\
Learner-learner interaction & 0.783 & 0.833 & 0.815 \\
Learner-teacher interaction & 0.651 & 0.584 & \\
\hline
\end{tabular}

Table 4 depicts discriminant analysis by comparing cross loadings between the study's various constructs. The current study used cross loadings to measure discriminant validity, which means that each indicator should load high on its own constructs but low on other constructs, as shown in Table 5. As a result, discriminant validity was obtained in this study due to the substantial differences across the constructs.

Table 5. Cross-loadings.

\begin{tabular}{cccc}
\hline & INTERA & LLI & LTI \\
\hline ITERA1 & 0.749 & 0.565 & 0.391 \\
ITERA2 & 0.814 & 0.693 & 0.527 \\
ITERA3 & 0.829 & 0.575 & 0.569 \\
ITERA4 & 0.809 & 0.661 & 0.580 \\
LLI1 & 0.625 & 0.820 & 0.459 \\
LLI2 & 0.625 & 0.816 & 0.439 \\
LLI3 & 0.534 & 0.772 & 0.325 \\
LLI4 & 0.656 & 0.853 & 0.496 \\
LLI5 & 0.711 & 0.881 & 0.572 \\
LLI6 & 0.734 & 0.851 & 0.582 \\
LTI1 & 0.612 & 0.596 & 0.857 \\
LTI2 & 0.632 & 0.542 & 0.874 \\
LTI3 & 0.380 & 0.342 & 0.772 \\
LTI4 & 0.561 & 0.478 & 0.824 \\
LTI5 & 0.440 & 0.340 & 0.808 \\
LTI6 & 0.480 & 0.481 & 0.746 \\
\hline
\end{tabular}

Note: INTERA = Interaction effectiveness, LLI = Learner-learner interaction, and LTI = Learner-teacher interaction

\subsubsection{Structural Model}

The structural model must be completed because it is the second step in analyzing the study's hypotheses. Different criteria must be used to evaluate the structural model [56]. As a result, the evaluation was conducted utilizing the PLS algorithm approach with bootstrapping. To evaluate the study's assumptions in Table 6, path coefficients were calculated using PLS with $p$-values and t-statistics (bootstrapping results). As a result, the PLS-SEM technique was used to determine the impact of the independent variables on interaction effectiveness. The outcomes of the hypothesis examination are summarized in Table 5, which shows that the values of the first hypothesis were " $t=11.991$ ", " $\beta=0.294$ ", and " $p=0.000$," and these values support the first hypothesis, which supports that the students have the perception that learner-learner interaction positively affect the effectiveness of online interaction. Similarly, the values of the second hypothesis were " $t=4.960$ ", " $\beta=0.294$ ", and " $p=0.000$ ", which are accepted and significant values, and this supports that the students perceive learner-teacher interaction positively affect the effectiveness of online interaction. This is critical for accepting the study hypotheses through the structural model. The results of the path evaluation ( $\mathrm{t}$-value and $p$-value), which were also utilized to establish the impact of the independent and dependent variables' connection, were used to validate and reject the study hypothesis. Table 6 and Figure 2 below illustrate the path coefficient values as well as the significance level of the relationships in the structural model, which shows that $\mathrm{H} 1$ and $\mathrm{H} 2$ are supported and significant. 
Table 6. Results of hypotheses testing.

\begin{tabular}{ccccccc}
\hline Hypothesis & Description & $\begin{array}{c}\text { Path } \\
\text { Coefficients }(\boldsymbol{\beta})\end{array}$ & t-Value & $p$-Values & $\begin{array}{c}\text { Significance } \\
\text { Level }\end{array}$ & Results \\
\hline H1 & LLI -> DV & 0.612 & 11.991 & 0.000 & $* * *$ & Supported \\
H2 & LTI -> DV & 0.294 & 4.960 & 0.000 & Supported \\
\hline
\end{tabular}

Note: ${ }^{* * *}$ Significant level $=1 \%(p<0.001)$.

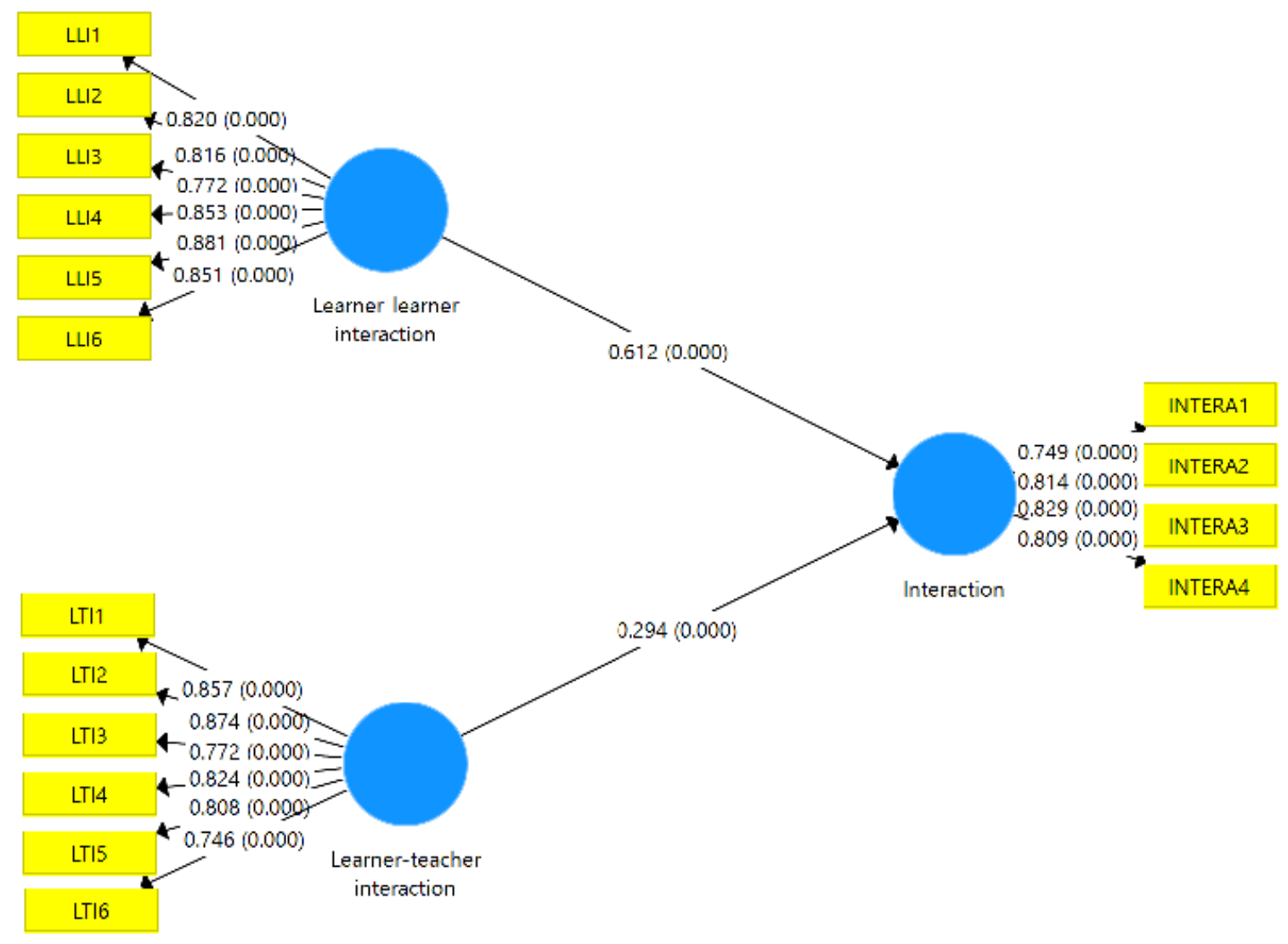

Figure 2. Structural model assessment with bootsrapping.

\subsubsection{Qualitative Data Analysis}

The follow-up interview supports the above findings, as most of the interviewed students appeared to positively evaluate and appreciate the interaction in these online writing courses and also elaborated their views by providing reasons behind their positive perception in the survey. It is evident that their positive perception of the online interaction is due to its role in mediating their understanding of the errors in writing and enhancing their writing (S2P6: "I am really satisfied with the interaction as it helps us to discover our errors and also think of great ideas in our writing").

In relation to learner-learner interaction, some interviewed students viewed peer interaction in the online writing courses as a way to exchange help or support in essay writing (S2P16: "Writing was difficult for me but you know? Interaction with my friend helped me out regarding most of the things that I didn't understand"). Other benefits of peer interaction are learning or developing important cognitive and social skills, such as collaboration or team work, thinking, and decision-making skills (S2P19: "It was an effective method to motivate us to develop our critical-thinking and learn how to work together and make decisions").

As far as learner-teacher interactions are concerned, most of the interviewed learners expressed their positive evaluation and appreciation of learner-teacher interactions (S1P16: "Not at all. I love and appreciate teacher's interaction all the time. It helped us to improve 
my weaknesses in writing"). Some students also recognized the value of interacting with the course instructor in seeking support and getting their questions about some writing aspects answered by them (S1P17: "I was able to ask my teacher for help when me and my pair could not understand some errors").

The interview also supported students' higher level of perception of learner-teacher interaction when compared with that of learner-learner interaction. Some students, when asked to compare both types of interaction in the interview, stated that although learnerlearner interaction was a good way to share ideas, learner-teacher interaction was better because they could understand their errors and how to correct them (S2P3: "Because it was by the help of the professor that I learned how to understand the mistakes and identify them and how to correct them").

Table 7 also displays additional themes extracted from the thematic analysis of the follow-up interview. These themes focus on the affordances of the three technological tools in facilitating interactions in the online writing courses. In this regard, interactions supported by WhatsApp, Google Docs, and Blackboard Collaborate were perceived as immediate or spontaneous, as the learners were able to engage in simultaneous exchange of information and feedback. Moreover, WhatsApp and Google Docs supported delayed or asynchronous interactional exchanges. Although these interactions had a delay in time between initiating and responding, they were valued for they provided them the opportunity to think well before exchanging information. Since learners were able to talk by voice of the Blackboard Collaborate Ultra while editing their Google Docs-based writing, such interactions were viewed by the majority of them as elaborative.

Table 7. Additional themes emerging from the follow-up interview.

\begin{tabular}{c} 
Sample Interview Responses \\
\hline Affordances \\
S2P3: We can communicate through the chat and comment boxes to review mistakes through Google Docs. \\
S1P5: So for me, I don't see any inconvenient thing about WhatsAap because I was online all the time and I \\
could check all messages and instantly reply. \\
S2P11: The interaction of the Blackboard was simultaneous and timely. \\
S1P6: Definitely. We don't have to wait for each other to be online at the same time to interact through \\
Google Docs, but we can comment on each other and respond later. \\
Slaborative
\end{tabular}

\subsection{Factors Affecting Learners' Perceived Interaction}

The qualitative analysis of the interview revealed more factors and challenges affecting learners' perceived interaction in the online writing courses. These factors were clustered into learner-related and technology-related challenges (Table 8). For learner-related challenges, experience in connecting the Google Docs-based writing to Blackboard Collaborate Ultra appeared an important factor for some learners that affected their perception of the interaction, though it was found to be of insignificant influence in the survey. Another important factor pertaining to learners is the unfair contribution of individual learners in few pairs to the interaction and peer work.

For those technological and technical factors, most of the interviewed learners admitted that online interaction was not sufficient, especially when the interaction occurred in the Google Docs text chat. In addition, interaction through instant messaging in the WhatsApp group seemed hard to follow. For those students who used only mobile phones to access their screencast discussions, they found it difficult to simultaneously discuss in Blackboard and edit their essays in Google Docs. Finally, the majority of students reported internet disconnection as a major issue hindering their perceived online interaction. 
Table 8. Themes emerging from the follow-up interview.

\begin{tabular}{|c|c|}
\hline Themes & Sample Interview Responses \\
\hline \multirow{2}{*}{ Learner-related } & $\begin{array}{l}\text { Previous experience: S1P3: It was hard for us because the first time we combined Google } \\
\text { Docs and Blackboard. }\end{array}$ \\
\hline & $\begin{array}{l}\text { Unfair contribution: S1P5: However, it does make things difficult when we saw little } \\
\text { contributions from my teammate to our discussion. }\end{array}$ \\
\hline \multirow{4}{*}{ Technological and technical-related } & $\begin{array}{l}\text { Insufficient: It is tough when you can't have face-to-face interaction but the interaction } \\
\text { through the chatting room of Google Docs is just not fast enough (S2P8). }\end{array}$ \\
\hline & $\begin{array}{l}\text { Hard to follow: However, the problem with WhatsApp was that it was sometimes hard you } \\
\text { know? I mean hard to follow all comments and read them. }\end{array}$ \\
\hline & $\begin{array}{l}\text { Access device: S2P14: I was telling my friend how to join me but he couldn't get it to be in } \\
\text { the Blackboard room and Google Docs at the same moment because he was using a } \\
\text { mobile phone. }\end{array}$ \\
\hline & $\begin{array}{l}\text { Internet connection: S2P13: So that's why I was wanting to do the discussion offline because } \\
\text { when I did it online, I had a problem with the Internet so I lost much of my work. }\end{array}$ \\
\hline
\end{tabular}

\section{Discussion}

Due to the challenges involved in engaging learners in interactions and sustaining such interactions in writing courses, especially during the COVID-19, the current paper reported an empirical study on how a university writing instructor in the KSA context sustained learners' interactions online through three different technological tools. Specifically, in answering the first research question, this study provides evidence on multidirectional interactions-learner-learner, teacher-learner, and learner-teacher interactions leveraged in the different writing stages: planning, writing, and revising through various digital tools. As learners plan and write their tasks in pairs, they are inclined to interact with each other, propose their task outlines, generate ideas, and make decisions on what and how to write using both instant messaging through WhatsApp and Google Docs. This supports previous research on the potential of instant messaging through WhatsApp for providing space for peer interactions and exchanges of information and ideas [44-46]. The study also corroborated the role of Google Docs when combined with other synchronous chatting tools in sustaining peer interactions in a multimodal manner-shifting from text to audio modes and using pictures and non-verbal language such as similes and facial expressions $[13,17]$.

In this study, learner-learner interaction was also extended by the Google Docs highlights discussed by the paired learners in Blackboard Collaborate Ultra. Such interaction showed learners' active engagement with feedback highlights of their errors, as they engaged in error negotiations and interpretations during the revision stage. Peer negotiations and interpretations of feedback are necessary for learners' successful accomplishment of peer-writing tasks [7,35]. Interpreting this finding from the interactionist approach [32], the EFL learners in this study engaged in peer interaction that showed their attempts and strategies in dealing with ambiguous feedback highlights of errors in their writing. What is interesting about learner-learner interactions is that they were facilitated by Blackboard Collaborate Ultra, which enabled learners to talk elaborately, record their talk, and switch from voice to text modes and vice versa while simultaneously revising their Google Docsbased writing. This is one of the contributions of the present study compared with earlier research on peer interactions in collaborative writing.

The potential of Blackboard Collaborate Ultra was highly pronounced when the learners engaged in teacher-learner interactions in the whole class discussions. Such interactions initiated by the course instructor were sustained through inclusion of not only target or student-writers, but also by those non-writers who contributed to the interaction through responses, suggestions, corrections, questions, and even explanations of highlighted errors in their peers' writing displayed on the Blackboard screen. This 
supports the interactive, multidirectional, and multimodal nature of learning and teaching through Blackboard [38,47,48,52].

In this study, learners also assumed active roles as interaction initiators because they initiated learner-teacher interaction, which demonstrated how learners seemed eager to seek feedback on certain confusing points in their writing and ask support from the course instructor in order to understand their errors. In this regard, Google Docs and also WhatsApp played a facilitative tool for such interaction. From the socio-constructivist perspective, this particular finding confirms the role of feedback dialogue in making an effective shift in learners' roles from passive receivers to active respondents and even feedback givers or providers [36,37,40,42,59].

In answering the second research question, learners' perceptions of the online interaction in these writing courses were at high levels overall and particularly in regard to learner-learner and learner-teacher interaction. This was also supported by learners' voices in the follow-up interview, as the majority of them positively evaluated and appreciated the interaction in the online writing courses due the opportunity for discussing and detecting their errors in writing. This result contradicts the results of previous studies on the moderate levels of learners' perceptions of interaction in online learning [50], as both studies reported moderately perceived interactions. This could be owing to the different courses investigated as, in the current study, the writing courses needed active interaction from learners and the instructor and, therefore, it was highly perceived.

In this study, learners' level of perception of learner-teacher interaction was even higher than that of their perception of learner-learner interaction. This indicates that leaner-teacher interaction appeared more useful for learners. The follow-up interview revealed several reasons behind this result, including the opportunity for learners to understand their errors when interacting with the instructor, their view of the teacher as a more knowledgeable person, and the chance to seek further clarifications from them. This finding does not belittle learner-learner interaction, as it is also an important source of support in writing, but rather it emphasizes learner-teacher interaction as an integral part of teaching writing online. In other words, both types of interactions reflected how learners referred to peers and the instructor as sources to consult and mediate their understanding of feedback highlights. This finding supports sociocultural theory [34] in terms of the concept of scaffolding or mediating as support provided by peers or even instructors in the process of collaborative writing [35].

In this study, the potential of technology in creating an interactive learning environment was emphasized by learners in the follow-up interview. In this regard, the three technological tools used in this study were viewed as effective tools that facilitate immediate or spontaneous interaction. Such interaction fosters learners' fast or immediate exchange of information, ideas, and negotiations [14,52]. Furthermore, Google Docs supports asynchronous (delayed time) interaction through its commenting feature. What was of interest is learners' perceived value of Blackboard Collaborate Ultra in allowing them to orally interact as much as they could while revising their texts.

In addressing the third research question, the qualitative data identified several factors affecting learners' perception of the online interaction in the writing courses. These factors were grouped into learner-related and technology-related. The follow-up interview revealed that learners' engagement in peer discussion of their Google Docs-based writing in Blackboard Collaborate Ultra was found to be difficult at the initial stage due to their first-time experience in using these combined technological tools. This implies that adequate training on how to use educational technologies for interaction is necessary for learners [49,51]. Moreover, technology-related factors and challenges affecting learners' perception of interaction were access devices, internet disconnection, WhatsApp chat confusion, and insufficient space for interaction in Google Docs. This supports the finding of [50], i.e., that interaction was affected by environmental factors, including the media. Such a result has positive implications for writing instructors. In order to promote learners' 
engagement and interaction in online learning, technology-related challenges should be minimized by supporting learners' accessibility of the online courses.

\section{Conclusions}

The current study explored how different technological tools were used by an instructor in sustaining learners' engagement and interaction in three online writing courses during COVID-19-related emergence learning. Being situated in a KSA university, the study revealed that interaction was sustained in a multidirectional and multimodal manner. It provided learners the opportunity to discuss their writing with peers and the instructor. Despite learners' high perception levels, the perceived value of interaction was affected by some factors and challenges related to learners and technology. The study suggested that instructors and teachers should make a good use of technology-combination in cultivating and maintaining learners' interaction in online language learning courses, including writing courses.

Despite the interesting insights into the role of technology combined with effective instructional strategies in sustaining learners' online interaction in writing courses offered by the present study, there are several limitations and implications for future research. The first limitation is that the current study was more process-oriented, as it focused on the processes of interaction rather than its effect or output. Future studies, therefore, can assess the effect of interaction on students' performance in writing. This can be achieved by comparing the scores of pre and post-interaction writing tasks. A second limitation is that the findings of the interaction analysis were reported qualitatively, but the occurrences of the different patterns of interaction were not counted. This, if taken into account in future studies, will probably provide useful insight into the dominating pattern(s) of interaction in writing courses. Moreover, due to the large number of students joining these writing courses, it was impossible to compare among individual learners or individual pairs in relation to how interaction was initiated and sustained. Finally, the purpose of this study was not to compare between the three technological tools, but they were discussed as part of our findings on the potential of technology in sustaining interaction in these courses.

Author Contributions: Conceptualization, M.A.S. and M.A.A.; methodology, M.A.S. and A.A.Y.; validation, M.A.S.; M.A.A. and A.A.Y.; formal analysis, M.A.S., M.A.A. and A.A.Y.; investigation, M.A.S.; writing—original draft preparation, M.A.S.; drafting, M.A.S., M.A.A. and A.A.Y. All authors have read and agreed to the published version of the manuscript.

Funding: The authors would like to thank Deanship of Scientific Research at Majmaah University for supporting this work under project number: R-2021-237. Thanks should be extended to Deanship of Scientific Research at Qassim University for the Fast Track Publication Initiative.

Institutional Review Board Statement: The study was conducted according to the guidelines of the Declaration of Majmaah University, and approved by the Institutional Review Board of Majmaah University (protocol code MUREC-Apr.22/COM-2021/27-4).

Informed Consent Statement: The consent forms have been obtained from the students.

Conflicts of Interest: The authors declare no conflict of interest.

\section{References}

1. Alghasab, M.; Hardman, J.; Handley, Z. Teacher-student interaction on wikis: Fostering collaborative learning and writing. Learn. Cult. Soc. Interact. 2019, 21, 10-20. [CrossRef]

2. Yeh, H.-C. Exploring how collaborative dialogues facilitate synchronous collaborative writing. Lang. Learn. Technol. 2014, 18, 23-37.

3. Rojas-Drummond, S.; Mercer, N. Scaffolding the development of effective collaboration and learning. Int. J. Educ. Res. 2003, 39, 99-111. [CrossRef]

4. Webb, N.M. The teacher's role in promoting collaborative dialogue in the classroom. Br. J. Educ. Psychol. 2009, 79, 1-28. [CrossRef]

5. Zeng, G.; Takatsuka, S. Text-based peer-peer collaborative dialogue in a computer-mediated learning environment in the EFL context. System 2009, 37, 434-446. [CrossRef] 
6. Alharbi, M.A. Exploring the potential of Google Doc in facilitating innovative teaching and learning practices in an EFL writing course. Innov. Lang. Learn. Teach. 2020, 14, 227-242. [CrossRef]

7. Saeed, A.M.; Ghazali, K. Asynchronous group review of EFL writing: Interactions and text revisions. Lang. Learn. Technol. 2017, 21, 200-226.

8. Kara, M. Transactional distance and learner outcomes in an online EFL context. Open Learn. J. Open Distance e-Learn. 2021, 36, 45-60. [CrossRef]

9. Dutta, B.; Peng, M.-H.; Chen, C.-C.; Sun, S.-L. Interpreting Usability Factors Predicting Sustainable Adoption of Cloud-Based E-Learning Environment during COVID-19 Pandemic. Sustainability 2021, 13, 9329. [CrossRef]

10. Kohnke, L.; Jarvis, A. Coping with English for Academic Purposes Provision during COVID-19. Sustainability 2021, $13,8642$. [CrossRef]

11. Alshaikh, K.; Maasher, S.; Bayazed, A.; Saleem, F.; Badri, S.; Fakieh, B. Impact of COVID-19 on the Educational Process in Saudi Arabia: A Technology-Organization-Environment Framework. Sustainability 2021, 13, 7103. [CrossRef]

12. Petchamé, J.; Iriondo, I.; Villegas, E.; Riu, D.; Fonseca, D. Comparing Face-to-Face, Emergency Remote Teaching and Smart Classroom: A Qualitative Exploratory Research Based on Students' Experience during the COVID-19 Pandemic. Sustainability 2021, 13, 6625. [CrossRef]

13. Choi, L.; Chung, S. Navigating online language teaching in uncertain times: Challenges and strategies of EFL educators in creating a sustainable technology-mediated language learning environment. Sustainability 2021, 13, 7664. [CrossRef]

14. Chen, J.C.; Dobinson, T.; Kent, S. Lecturers' perceptions and experiences of Blackboard Collaborate as a distance learning and teaching tool via Open Universities Australia (OUA). Open Learn. J. Open Distance e-Learn. 2020, 35, 222-235. [CrossRef]

15. Ishtaiwa, F.F.; Aburezeq, I.M. The impact of Google Docs on student collaboration: A UAE case study. Learn. Cult. Soc. Interact. 2015, 7, 85-96. [CrossRef]

16. Liang, M.-Y. Using synchronous online peer response groups in EFL writing: Revision-related discourse. Lang. Learn. Technol. 2010, 14, 45-64.

17. Elola, I.; Oskoz, A. Collaborative writing: Fostering foreign language and writing conventions development. Lang. Learn. Technol. 2010, 14, 51-71.

18. Saeed, A.M.; Al Qunayeer, H.S. Exploring teacher interactive e-feedback on students' writing through Google Docs: Factors promoting interactivity and potential for learning. Lang. Learn. J. 2020, 1-18. [CrossRef]

19. Cho, H. Synchronous web-based collaborative writing: Factors mediating interaction among second-language writers. J. Second. Lang. Writ. 2017, 36, 37-51. [CrossRef]

20. Wood, J. Making peer feedback work: The contribution of technology-mediated dialogic peer feedback to feedback uptake and literacy. Assess. Eval. High. Educ. 2021, 1-20. [CrossRef]

21. Viberg, O.; Grönlund, Å.; Andersson, A. Integrating digital technology in mathematics education: A Swedish case study. Interact. Learn. Environ. 2020, 1-12. [CrossRef]

22. Li, M. Computer-mediated collaborative writing in L2 contexts: An analysis of empirical research. Comput. Assist. Lang. Learn. 2018, 31, 882-904. [CrossRef]

23. Li, M.; Kim, D. One wiki, two groups: Dynamic interactions across ESL collaborative writing tasks. J. Second. Lang. Writ. 2016, 31, 25-42. [CrossRef]

24. Storch, N. Collaborative writing. Lang. Teach. 2019, 52, 40-59. [CrossRef]

25. Abrams, Z. Exploring collaboratively written L2 texts among first-year learners of German in Google Docs. Comput. Assist. Lang. Learn. 2016, 29, 1259-1270. [CrossRef]

26. Elabdali, R.; Arnold, N. Group Dynamics across Interaction Modes in L2 Collaborative Wiki Writing. Comput. Compos. 2020, 58, 102607. [CrossRef]

27. Wigglesworth, G.; Storch, N. What role for collaboration in writing and writing feedback. J. Second. Lang. Writ. 2012, 21, 364-374. [CrossRef]

28. Merkel, W. Role reversals: A case study of dialogic interactions and feedback on L2 writing. J. Second. Lang. Writ. 2018, 39, 16-28. [CrossRef]

29. Steen-Utheim, A.; Wittek, A.L. Dialogic feedback and potentialities for student learning. Learn. Cult. Soc. Interact. 2017, 15, 18-30. [CrossRef]

30. Liu, M.; Liu, L.; Liu, L. Group awareness increases student engagement in online collaborative writing. Internet High. Educ. 2018, 38, 1-8. [CrossRef]

31. Williams, J.; Severino, C. The writing center and second language writers. J. Second. Lang. Writ. 2004, 3, 165-172. [CrossRef]

32. Long, M.H. Input, Interaction, and Second Language Acquisition; University of California: Los Angeles, CA, USA, 1980.

33. Pica, T. Research on negotiation: What does it reveal about second-language learning conditions, processes, and outcomes? Lang. Learn. 1994, 44, 493-527. [CrossRef]

34. Vygotsky, L.S. Socio-cultural theory. Mind Soc. 1978, 6, 52-58.

35. Hanjani, M.A.; Li, L. Exploring L2 writers' collaborative revision interactions and their writing performance. System 2014, 44, 101-114. [CrossRef]

36. Gikandi, J.; Morrow, D. Designing and implementing peer formative feedback within online learning environments. Technol. Pedagog. Educ. 2016, 25, 153-170. [CrossRef] 
37. Orsmond, P.; Maw, S.J.; Park, J.R.; Gomez, S.; Crook, A.C. Moving feedback forward: Theory to practice. Assess. Eval. High. Educ. 2013, 38, 240-252. [CrossRef]

38. Chen, S.; Ouyang, F.; Jiao, P. Promoting student engagement in online collaborative writing through a student-facing social learning analytics tool. J. Comput. Assist. Learn. 2021. [CrossRef]

39. Schillings, M.; Roebertsen, H.; Savelberg, H.; Dolmans, D. A review of educational dialogue strategies to improve academic writing skills. Act. Learn. High. Educ. 2018. [CrossRef]

40. Zhu, Q.; Carless, D. Dialogue within peer feedback processes: Clarification and negotiation of meaning. High. Educ. Res. Dev. 2018, 37, 883-897. [CrossRef]

41. Yang, M.; Carless, D. The feedback triangle and the enhancement of dialogic feedback processes. Teach. High. Educ. 2013, 18, 285-297. [CrossRef]

42. Adie, L.; van der Kleij, F.; Cumming, J. The development and application of coding frameworks to explore dialogic feedback interactions and self-regulated learning. Br. Educ. Res. J. 2018, 44, 704-723. [CrossRef]

43. Godwin-Jones, R. Second language writing online: An update. Lang. Learn. Technol. 2018, 22, 1-15.

44. Sung, -T.Y.; Chang, K.-E.; Liu, T.-C. The effects of integrating mobile devices with teaching and learning on students' learning performance: A meta-analysis and research synthesis. Comput. Educ. 2016, 94, 252-275. [CrossRef]

45. Wrigglesworth, J. Using smartphones to extend interaction beyond the EFL classroom. Comput. Assist. Lang. Learn. 2020, 33, 413-434. [CrossRef]

46. Xu, Q.; Peng, H. Investigating mobile-assisted oral feedback in teaching Chinese as a second language. Comput. Assist. Lang. Learn. 2017, 30, 173-182. [CrossRef]

47. Satar, M.H.; Wigham, C.R. Multimodal instruction-giving practices in webconferencing-supported language teaching. System 2017, 70, 63-80. [CrossRef]

48. Torun, E.D. Synchronous interaction in online learning environments with Adobe Connect Pro. Procedia-Soc. Behav. Sci. 2013, 106, 2492-2499. [CrossRef]

49. Ekwunife-Orakwue, C.K.; Teng, T.-L. The impact of transactional distance dialogic interactions on student learning outcomes in online and blended environments. Comput. Educ. 2014, 78, 414-427. [CrossRef]

50. Huang, X.; Chandra, A.; DePaolo, C.A.; Simmons, L.L. Understanding transactional distance in web-based learning environments: An empirical study. Br. J. Educ. Technol. 2016, 47, 734-747. [CrossRef]

51. Vasiloudis, G.; Koutsouba, M.; Giossos, Y.; Mavroidis, I. Transactional distance and autonomy in a distance learning environment. Eur. J. Open Distance E-Learn. 2015, 18, 114-122. [CrossRef]

52. Montanero, M.; Marques, M.-J. "Explain it on the blackboard". An analysis of the educational interaction in mirror assessment activities. Learn. Cult. Soc. Interact. 2019, 22, 100247. [CrossRef]

53. Creswell, J.W. Qualitative, Quantitative and Mixed Methods Approaches; Sage: Thousand Oaks, CA, USA, 2014.

54. Hair, F.J.; Ringle, C.; Sarstedt, M. Journal of Marketing Theory and Practice PLS-SEM: Indeed a silver bullet. J. Mark. Theory Pract. 2011, 19, 139-152. [CrossRef]

55. Chin, W.W. How to Write Up and Report PLS Analyses, in Handbook of Partial Least Squares; Springer: Berlin/Heidelberg, Germany, 2010; pp. 655-690.

56. Hair, J.F., Jr.; Hult, G.T.M.; Ringle, C.M.; Sarstedt, M. A primer on Partial Least Squares Structural Equation Modeling (PLS-SEM); Sage Publications: Thousand Oaks, CA, USA, 2021.

57. Ramayah, T.; Cheah, J.; Chuah, F.; Ting, H.; Memon, M.A. Partial Least Squares Structural Equation Modeling (PLS-SEM) Using SmartPLS 3.0.; Pearson: Kuala Lumpur, Malaysia, 2018.

58. Fornell, C.; Larcker, D.F. Evaluating structural equation models with unobservable variables and measurement error. J. Mark. Res. 1981, 18, 39-50. [CrossRef]

59. Gikandi, W.J.; Morrow, D.; Davis, N.E. Online formative assessment in higher education: A review of the literature. Comput. Educ. 2011, 57, 2333-2351. [CrossRef] 